\title{
A genetically-encoded chloride and pH sensor for dissociating ion dynamics in the nervous system
}

\author{
Joseph V. Raimondo ${ }^{1,2}$, Bradley Joyce ${ }^{3}$, Louise Kay ${ }^{1}$, Theresa Schlagheck ${ }^{1}$, Sarah E. Newey ${ }^{1}$, \\ Shankar Srinivas ${ }^{3}$ and Colin J. Akerman ${ }^{1}$ * \\ Department of Pharmacology, University of Oxford, Oxford, UK \\ 2 UCT/MRC Receptor Biology Unit, Division of Medical Biochemistry, Faculty of Health Sciences, Institute of Infectious Disease and Molecular Medicine, \\ University of Cape Town, Cape Town, South Africa \\ ${ }^{3}$ Department of Physiology, Anatomy and Genetics, University of Oxford, Oxford, UK
}

\section{Edited by:}

Arianna Maffei, SUNY Stony Brook, USA

\section{Reviewed by:}

Melanie A. Woodin, University of Toronto, Canada

Corette J. Wierenga, Utrecht

University, Netherlands

*Correspondence:

Colin J. Akerman, Department of Pharmacology, University of Oxford,

Mansfield Road, OX1 3QT,

Oxford, UK

e-mail: colin.akerman@

pharm.ox.ac.uk
Within the nervous system, intracellular $\mathrm{Cl}^{-}$and $\mathrm{pH}$ regulate fundamental processes including cell proliferation, metabolism, synaptic transmission, and network excitability. $\mathrm{Cl}^{-}$and $\mathrm{pH}$ are often co-regulated, and network activity results in the movement of both $\mathrm{Cl}^{-}$and $\mathrm{H}^{+}$. Tools to accurately measure these ions are crucial for understanding their role under physiological and pathological conditions. Although genetically-encoded $\mathrm{Cl}^{-}$and $\mathrm{pH}$ sensors have been described previously, these either lack ion specificity or are unsuitable for neuronal use. Here we present ClopHensorN-a new genetically-encoded ratiometric $\mathrm{Cl}^{-}$and $\mathrm{pH}$ sensor that is optimized for the nervous system. We demonstrate the ability of ClopHensorN to dissociate and simultaneously quantify $\mathrm{Cl}^{-}$and $\mathrm{H}^{+}$concentrations under a variety of conditions. In addition, we establish the sensor's utility by characterizing activity-dependent ion dynamics in hippocampal neurons.

Keywords: genetic reporters, chloride sensors, $\mathrm{pH}$ sensors, intracellular chloride, intracellular pH, neural activity, fluorescence microscopy

\section{INTRODUCTION}

Chloride $\left(\mathrm{Cl}^{-}\right)$and hydrogen $\left(\mathrm{H}^{+}\right)$ions are fundamental to a wide range of processes within the nervous system including cell division, volume regulation, migration, metabolism, synaptic vesicle loading, network excitability, and fast synaptic inhibition (Tabb et al., 1992; Denker and Barber, 2002; Putney and Barber, 2003; Farrant and Kaila, 2007). $\mathrm{Cl}^{-}$and $\mathrm{H}^{+}$are often co-regulated (Russell and Boron, 1976; Kaila et al., 1989) and activity-dependent neuronal processes typically involve either the related, or independent, flux of both $\mathrm{Cl}^{-}$and $\mathrm{H}^{+}$ions (Chesler, 2003; Farrant and Kaila, 2007). Whilst intracellular $\mathrm{Cl}^{-}$concentration $\left(\left[\mathrm{Cl}^{-}\right]_{\mathrm{i}}\right)$ and the negative logarithm of intracellular $\mathrm{H}^{+}$ ion concentration $\left(\mathrm{pH}_{\mathrm{i}}\right)$ are known to affect network excitability, network activity itself can generate shifts in the intracellular concentrations of these two ions (Isomura et al., 2003; Raimondo et al., 2012b). This reciprocal relationship means that tools to accurately and independently measure $\left[\mathrm{Cl}^{-}\right]_{\mathrm{i}}$ and $\mathrm{pH}_{\mathrm{i}}$ are important for understanding the separate and combined roles that these ions play during physiological and pathological network states.

$\mathrm{Cl}^{-}$or $\mathrm{pH}$ sensitive microelectrodes generated some of the earliest measurements of $\left[\mathrm{Cl}^{-}\right]_{\mathrm{i}}$ and $\mathrm{pH}_{\mathrm{i}}$. However, due to their size and potential effect upon cell integrity, the use of these microelectrodes has been most successful in large invertebrate neurons. Fluorescent dyes have also been widely used to report both $\mathrm{Cl}^{-}$and $\mathrm{pH}$. However, the most sensitive $\mathrm{Cl}^{-}$ dyes, such as $\mathrm{N}$-(ethoxycarbonylmethyl)-6-methoxyquinolinium bromide (MQAE), are not ratiometric and so do not measure absolute $\mathrm{Cl}^{-}$concentrations. In addition, these dyes tend to suffer from problems associated with toxicity, rapid bleaching, and cell leakage (Bregestovski et al., 2009). In contrast, the most popular $\mathrm{pH}$ sensitive dyes, such as $2^{\prime}-7^{\prime}$-bis(carboxyethyl)-5(6)carboxyfluoroscein (BCECF) and the seminaphthorhodafluors (SNARFs), are well tolerated and offer ratiometric estimation of absolute $\mathrm{pH}$. Nonetheless, these dyes can interfere with endogenous $\mathrm{H}^{+}$ion transport mechanisms and cannot be genetically targeted to cell types or subcellular compartments (Gatto and Milanick, 1993).

The discovery that green fluorescent protein (GFP) demonstrates inherent $\mathrm{Cl}^{-}$and $\mathrm{pH}$ fluorescence sensitivity marked the beginning of an effort to develop genetically-encoded reporters of $\mathrm{Cl}^{-}$or $\mathrm{pH}$ (Jayaraman et al., 2000; Kuner and Augustine, 2000). One approach has been to create fusions of two GFP mutants: yellow fluorescent protein (YFP) and cyan fluorescent protein (CFP). Whereas YFP emission is reduced by $\mathrm{Cl}^{-}$or $\mathrm{H}^{+}$ binding, CFP fluorescence is relatively unaffected and serves as a fluorescence resonance energy transfer (FRET) donor for YFP. These fusion proteins are therefore useful as ratiometric reporters of either $\left[\mathrm{Cl}^{-}\right]_{\mathrm{i}}$ or $\mathrm{pH}_{\mathrm{i}}$, and proteins within this group include Clomeleon, $\mathrm{Cl}$-sensor, $\mathrm{YFpH}$, and the pHlameleons (Kuner and Augustine, 2000; Awaji and Hirasawa, 2001; Esposito et al., 2008; Markova et al., 2008). Unfortunately, YFP's dual sensitivity to $\mathrm{Cl}^{-}$ and $\mathrm{pH}$ complicates the interpretation of measurements using these reporters and means that if the concentration of both ions change, it is not possible to dissociate the underlying ion fluxes. This is compounded by the fact that cellular processes often involve concomitant changes in both $\mathrm{Cl}^{-}$and $\mathrm{H}^{+}$ion concentration (Russell and Boron, 1976; Kaila et al., 1989). Whilst other genetically-encoded $\mathrm{pH}$ indicators have been developed, such as 
pHlourin (Miesenböck et al., 1998) (RaGFP) and the deGFPs (Hanson et al., 2002), their susceptibility to artifacts based on $\mathrm{Cl}^{-}$ sensitivity has not been well-characterized.

This issue was addressed by the introduction of ClopHensor (Arosio et al., 2010) - a fusion protein that is able to simultaneously measure concentrations of both $\mathrm{Cl}^{-}$and $\mathrm{H}^{+}$ions and has been shown to function in heterologous cell lines (Arosio et al., 2010; Mukhtarov et al., 2013). ClopHensor is composed of the $\mathrm{Cl}^{-}$and $\mathrm{pH}$ sensitive GFP mutant, $\mathrm{E}^{2} \mathrm{GFP}$, fused to monomeric DsRed. Here we identify problems associated with the use of ClopHensor in the nervous system. We therefore reengineer and improve this reporter, and present "ClopHensorN," a new, genetically-encoded ratiometric $\mathrm{Cl}^{-}$and $\mathrm{pH}$ sensor that is optimized to dissociate ion dynamics in neuronal cell types. We demonstrate the ability of ClopHensorN to simultaneously quantify $\mathrm{Cl}^{-}$and $\mathrm{pH}$ fluxes under a variety of conditions. Expression of ClopHensorN in hippocampal neurons enables us to dissect changes in intracellular $\mathrm{Cl}^{-}$and $\mathrm{pH}$ in response to network activity, which would not be possible with previous reporters.

\section{MATERIALS AND METHODS DNA CONSTRUCTS AND SUBCLONING}

The original ClopHensor construct (Arosio et al., 2010), and ClopHensor fused to two palmitoylation sites ("PalmPalmClopHensor"), were kindly provided by Daniele Arosio (University of Trento; Addgene plasmids 25938 and 25940). ClopHensor was moved into the expression vector $\mathrm{pBJ} 1$ under the control of a chicken beta actin (CAG) promoter and the DsRed monomer was replaced with either mCherry or tandem dimer tomato (tdTomato). The new constructs maintained the 20 amino acid linker sequence RGSASGGGGGLVPRGSASGA between $E^{2} \mathrm{GFP}$ and the red fusion protein, with the addition of two amino acids (TG) at the C-terminal end of the linker. Western blotting experiments confirmed that both the original ClopHensor and the new ClopHensorN construct generated $>90 \%$ full-length fusion proteins (data not shown). Upon publication the constructs presented here will be made freely available from the non-profit service Addgene (http:// www.addgene.org/).

\section{SLICE PREPARATION AND DNA TRANSFECTION}

Rat organotypic hippocampal slice cultures were prepared using a method similar to that described by Stoppini et al. (1991). Briefly, 7 day old male Wistar rats were killed in accordance with the UK Animals Scientific Procedures Act 1986. The brains were extracted and placed in cold $\left(4^{\circ} \mathrm{C}\right)$ Geys Balanced Salt Solution (GBSS), supplemented with D-glucose $(34.7 \mathrm{mM})$. All reagents were purchased from Sigma-Aldrich, unless stated. The hemispheres were separated and individual hippocampi were removed and immediately sectioned into $350 \mu \mathrm{m}$ thick slices on a McIlwain tissue chopper. Slices were rinsed in cold dissection media, placed onto Millicell-CM membranes and maintained in culture media containing 25\% EBSS, 50\% MEM, 25\% heat-inactivated horse serum, glucose, and B27 (Invitrogen). Slices were incubated at $36^{\circ} \mathrm{C}$ in a $5 \% \mathrm{CO}_{2}$ humidified incubator before transfection. Neurons were biolistically transfected after 4-7 days in vitro using a Helios Gene
Gun (120 psi; Bio-Rad). Fifty microgram of target DNA was precipitated onto $25 \mathrm{mg}$ of $1.6 \mu \mathrm{m}$ diameter gold microcarriers and bullets generated in accordance with the manufacturer's instructions (Bio-Rad). Biolistic delivery of target DNA resulted in sparse transfection rates (typically less than 10 cells per slice) and recordings were performed 2-7 days post-transfection. For a subset of experiments ClophensorN was expressed in mouse cortex by in utero electroporation. In utero electroporation was carried out on E14.5 C57BL6/J (Jackson Laboratory) mouse embryos. Dams were anesthetized using isoflorane (3\% for induction, $2-2.5 \%$ for surgery) and the uterine horns exposed by laparotomy. Each embryo was injected through the uterine wall with 0.5-1 ul ClopHensorN plasmid ( $2 \mathrm{ug} / \mathrm{ul}$ ) in PBS with $0.03 \%$ fast green (Sigma) using a thin-walled glass pipette (WPI) pulled to a $\sim 50 \mu \mathrm{m}$ tip. Paddle electrodes (Nepagene, CUY650) were used to deliver five $50 \mathrm{~ms}, 42 \mathrm{~V}$ pulses at $1 \mathrm{~Hz}$ from a square pulse generator (BTX, ECM 830). Embryos were kept moist during the surgery by applying warm sterile PBS. Following electroporation the uterine horns were replaced and the dam allowed to recover and litter as normal. At postnatal day 21 the mice were killed and the brain rapidly removed and placed in ice-cold $\left(0\right.$ to $\left.+4^{\circ} \mathrm{C}\right)$ artificial cerebro-spinal fluid (ACSF), bubbled with $95 \% \mathrm{O}_{2} / 5 \% \mathrm{CO}_{2}$. Coronal cortical slices (350-400 $\mu \mathrm{m}$ thickness) were cut using a vibrating microtome (Microm HM650V, Carl Zeiss Ltd) and slices were maintained in an interface chamber between humidified carbogen gas $\left(95 \% \mathrm{O}_{2}, 5 \% \mathrm{CO}_{2}\right)$ and ACSF (at $20-25^{\circ} \mathrm{C}$ ). After recovering for at least $1 \mathrm{~h}$, the slices were mounted on coverslips (coated with $0.1 \%$ poly-L-lysine in ultrapure $\mathrm{H}_{2} \mathrm{O}$ ) before being transferred to the recording chamber for imaging.

\section{ELECTROPHYSIOLOGICAL RECORDINGS AND ACTIVITY-DEPENDENT MANIPULATIONS}

Organotypic hippocampal slices or acute cortical slices were transferred to a recording chamber and continuously superfused with 95\% $\mathrm{O}_{2} / 5 \% \quad \mathrm{CO}_{2}$ oxygenated ACSF, warmed to $32-35^{\circ} \mathrm{C}$. The composition of the "standard" ACSF was (in $\mathrm{mM}): \mathrm{NaCl}(120), \mathrm{KCl}(3), \mathrm{MgCl}_{2}$ (2), $\mathrm{CaCl}_{2}$ (2), $\mathrm{NaH}_{2} \mathrm{PO}_{4}$ (1.2), $\mathrm{NaHCO}_{3}$ (23), D-Glucose (11). The $\mathrm{pH}$ was adjusted to be between 7.35 and 7.40 using $\mathrm{NaOH}$. Synchronous network activity was induced by switching bath perfusion of slices with normal ACSF to nominally $\mathrm{Mg}^{2+}$-free ACSF (Anderson et al., 1986) $\left(\mathrm{Mg}^{2+}\right.$ omitted from standard ACSF) or nominally $\mathrm{Cl}^{-}$free ACSF (Yamamoto and Kawai, 1967) $\left(\mathrm{NaCl}, \mathrm{MgCl}_{2}\right.$ and $\mathrm{CaCl}_{2}$ of standard ACSF replaced with $120 \mathrm{mM}$ sodium D-gluconate, $1 \mathrm{mM} \mathrm{MgSO}_{4}$ and $3 \mathrm{mM}$ calcium D-gluconate, respectively). Patch pipettes of $3-5 \mathrm{MOhm}$ tip resistance were pulled from filamental borosilicate glass capillaries $(1.2 \mathrm{~mm}$ outer diameter, $0.69 \mathrm{~mm}$ inner diameter; Harvard Apparatus Ltd), using a horizontal puller (Sutter P-97). For whole-cell recordings, pipettes were filled with an internal solution containing (in $\mathrm{mM}$ ): $\mathrm{K}$ gluconate (130), $\mathrm{NaCl}(10), \mathrm{CaCl}_{2}$ (0.1333), $\mathrm{MgCl}_{2}$ (2), EGTA (1), $\mathrm{KCl}(4)$, and HEPES (10). For the $\mathrm{GABA}_{\mathrm{A}}$ receptor activation experiments a cesium-based internal solution was used containing (in mM): cesium gluconate (120), $40 \mathrm{mM}$ HEPES (40), $\mathrm{NaCl}$ (4), ATP-Mg (2), Na-GTP (0.3), MQX-314 (0.2) and biocytin $(4 \mathrm{mg} / \mathrm{ml})$. The osmolarity of internal solutions was adjusted to $290 \mathrm{mOsM}$ and the $\mathrm{pH}$ was adjusted to 7.38 with $\mathrm{KOH}$. 
Pyramidal neurons within the CA1 and CA3 regions were visualized under a $40 \times$ water-immersion objective (Leica) and targeted for recording. Patch-clamp recordings were made using an Axopatch 1D or Axoclamp 2B amplifier (Axon Instruments). Data was acquired with WinWCP Strathclyde Whole Cell Analysis software (V.3.9.7; University of Strathclyde) before being exported to the MATLAB environment (MathWorks) for further analysis using customized scripts. Some statistical analysis was performed using GraphPad Prism version 5.00 (GraphPad Software). Data are reported as mean \pm SEM.

$\mathrm{GABA}_{\mathrm{A}}$ receptors were activated either by exogenous application of GABA or by electrical stimulation of GABAergic afferents. Short "puffs" of GABA $(200 \mu \mathrm{M})$ were applied via patch pipette positioned close to the soma and connected to a picospritzer (20 psi for $20 \mathrm{~ms}$; General Valve). Synaptic $\mathrm{GABA}_{\mathrm{A}}$ receptor activation was achieved by stimulating afferents using a bipolar stimulating electrode (Frederick Haer Company) placed in stratum radiatum, 300-400 $\mu \mathrm{m}$ from the recorded cell (Pouille and Scanziani, 2001). Simultaneous activation of glutamatergic receptors was prevented using bath application of kynurenic acid ( $2 \mathrm{mM})$.

\section{IMAGING AND CALIBRATING INTRACELLULAR CI- AND pH}

Imaging was performed using an upright Leica SP2 AOBS laser scanning confocal microscope equipped with a $40 \mathrm{x}$ water immersion objective (NA 0.8). To determine whether expression of ClopHensor and ClopHensor-derived constructs (including PalmPalm-ClopHensor) resulted in corresponding expression of $\mathrm{E}^{2} \mathrm{GFP}$ and the fused red fluorophore (either DsRed, mCherry or TdTomato), cells were excited at $488 \mathrm{~nm}$ (for $\mathrm{E}^{2} \mathrm{GFP}$, "green channel") and at $594 \mathrm{~nm}$ (for the red fluorophores, "red channel"). Emission was collected by separate photomultiplier tubes (PMTs): between 500 and $550 \mathrm{~nm}$ for the green channel and between 650 and $700 \mathrm{~nm}$ for the red channel. In a blinded manner, cells expressing each construct were counted. The number of cells demonstrating aggregates (examples Figures $\mathbf{1 B}, \mathbf{C}$ ) as a fraction of total expressing cells was recorded. Cells were counted as aggregated if there was an area of increased red fluorescence that was not matched by an increase in green fluorescence.

For intracellular $\mathrm{Cl}^{-}$and $\mathrm{pH}$ imaging ClopHensorN was used as a ratiometric indicator by excitation and was excited sequentially at 458, 488, and $594 \mathrm{~nm}$. Emission was collected between 500 and $550 \mathrm{~nm}$ with a single PMT when excited at 458 and $488 \mathrm{~nm}$, but between 650 and $700 \mathrm{~nm}$ with a second PMT when excited at $594 \mathrm{~nm}$. Images were exported to the MATLAB programming environment where background was subtracted and fluorescence averaged within regions of interest selected from the soma of individual cells. To correct for fluctuations in laser intensity, a photodiode (sample rate $10 \mathrm{kHz}$ ) recorded laser power output during imaging (Zucker and Price, 2001; Arosio et al., 2010) and the resulting data was used to correct fluorescence ratios offline by a factor $\alpha$ (for $\left.\mathrm{R}_{\mathrm{pH}}\right)$ and $\alpha_{2}$ (for $\mathrm{R}_{\mathrm{Cl}}$ ), see Figure $2 \mathrm{~B}$.

$$
\begin{aligned}
\alpha & =0.5 \div\left(I_{488} / I_{458}\right) \\
\text { and } \alpha_{2} & =0.5 \div\left(I_{458} / I_{594}\right)
\end{aligned}
$$

where $I_{458}, I_{488}$, and $I_{594}$ are the laser powers measured by the photodiode for excitation with the 458, 488, and $594 \mathrm{~nm}$ lasers, respectively.
In order to determine $\mathrm{pH}_{\mathrm{i}}$ using ClopHensorN, laser power corrected excitation fluorescence ratios $\left(\alpha \mathrm{R}_{\mathrm{pH}}\right)$ were measured as follows:

$$
\alpha \mathrm{R}_{\mathrm{pH}}=F_{488} / F_{458}
$$

$F_{488}$ and $F_{458}$ are the fluorescence recorded using excitation with the 488 and $458 \mathrm{~nm}$ lasers. The formation of a 1:1 analyte-sensor complex results in an equilibrium described by the Grynkiewicz equation (Grynkiewicz et al., 1985; Arosio et al., 2010), which can be written for ClopHensorN as follows:

$$
\mathrm{pH}_{\mathrm{i}}=\mathrm{pK}_{\mathrm{a}}+\log \left(\frac{\alpha \mathrm{R}_{\mathrm{pH}}-\alpha \mathrm{R}_{\mathrm{A}}}{\alpha \mathrm{R}_{\mathrm{B}}-\alpha \mathrm{R}_{\mathrm{pH}}}\right)+\log \left(\frac{F_{458, \mathrm{~A}}}{F_{458, \mathrm{~B}}}\right)
$$

$\alpha R_{\mathrm{A}}$ and $\alpha R_{\mathrm{B}}$ are the values of $\alpha \mathrm{R}_{\mathrm{pH}}$ for ClopHensorN in its most acidic and basic forms, respectively. Likewise, $F_{458, \mathrm{~A}}$ and $F_{458, \text { B }}$ reflect the emission upon excitation at $458 \mathrm{~nm}$, when the ratiometric indicator is in its acidic and basic form. $\mathrm{pK}_{\mathrm{a}}$ is the acid dissociation constant of the indicator. Due to the fact that ClopHensorN has a $\mathrm{pH}$ isobestic point at $458 \mathrm{~nm}$, fluorescence is $\mathrm{pH}$ insensitive when excited at this wavelength. That is, $F_{458, \mathrm{~A}}=$ $F_{458, \text { B }}$. Calibration data was therefore fitted using the following rearranged version of Equation 1:

$$
\alpha \mathrm{R}_{\mathrm{pH}}=\frac{\alpha \mathrm{R}_{\mathrm{B}} 10^{\mathrm{pH}-\mathrm{pK}_{\mathrm{A}}}+\alpha \mathrm{R}_{\mathrm{A}}}{1+10^{\mathrm{pH}-\mathrm{pK}_{\mathrm{A}}}}
$$

this allowed the $\mathrm{pKa}$ of ClopHensorN to be determined and $\mathrm{pH}_{\mathrm{i}}$ to be calculated from measured fluorescence ratios $\left(\alpha \mathrm{R}_{\mathrm{pH}}\right)$ during subsequent experiments.

Having determined $\mathrm{pH}_{\mathrm{i}},\left[\mathrm{Cl}^{-}\right]_{\mathrm{i}}$ could be calculated using the laser power corrected excitation fluorescence ratio $\left(\alpha_{2} \mathrm{R}_{\mathrm{Cl}}\right)$

$$
\alpha_{2} \mathrm{R}_{\mathrm{Cl}}=F_{458} / F_{594}
$$

respectively. The Grynkiewicz equation for using ClopHensorN as a $\mathrm{Cl}^{-}$indicator can be written as:

$$
\left[\mathrm{Cl}^{-}\right]_{\mathrm{i}}=\mathrm{K}_{\mathrm{d}}^{\mathrm{Cl}}\left[\mathrm{pH}_{\mathrm{i}}\right]\left(\frac{\alpha_{2} \mathrm{R}_{\mathrm{Cl}}-\alpha_{2} R_{\text {free }}}{\alpha_{2} R_{\text {bound }}\left[\mathrm{pH}_{\mathrm{i}}\right]-\alpha_{2} \mathrm{R}_{\mathrm{Cl}}}\right)\left(\frac{F_{594, \text { free }}}{F_{594, \text { bound }}}\right)
$$

$F_{594 \text {,free }}$ and $F_{594, \text { bound }}$ reflect the fluorescence after excitation with the $594 \mathrm{~nm}$ when the ClopHensorN is in its $\mathrm{Cl}^{-}$free and $\mathrm{Cl}^{-}$bound forms. However, as the fluorescence of TdTomato is insensitive to $\mathrm{Cl}^{-}, \frac{F_{594, \text { free }}}{F_{594, \text { bound }}}=1$ and Equation 3 can be simplified to:

$$
\left[\mathrm{Cl}^{-}\right]_{\mathrm{i}}=\mathrm{K}_{\mathrm{d}}^{\mathrm{Cl}}\left[\mathrm{pH} \mathrm{i}_{\mathrm{i}}\right]\left(\frac{\alpha_{2} \mathrm{R}_{\mathrm{Cl}}-\alpha_{2} R_{\text {free }}}{\alpha_{2} R_{\text {bound }}\left[\mathrm{pH} \mathrm{H}_{\mathrm{i}}\right]-\alpha_{2} \mathrm{R}_{\mathrm{Cl}}}\right)
$$

$K_{\mathrm{d}}^{\mathrm{Cl}}\left[\mathrm{pH}_{\mathrm{i}}\right]$ is the $\mathrm{Cl}^{-}$dissociation constant, which is dependent on $\mathrm{pH}$ (Arosio et al., 2010). $\alpha_{2} R_{\text {free }}$ is the maximum value of $\alpha_{2} R_{\mathrm{Cl}}$, reflecting $\alpha_{2} R_{\mathrm{Cl}}$ where no $\mathrm{Cl}^{-}$is bound to ClopHensorN. In contrast, $\alpha_{2} R_{\text {bound }}\left[\mathrm{pH}_{\mathrm{i}}\right]$ is the minimum value of $\alpha_{2} R_{\mathrm{Cl}}$, reflecting $\alpha_{2} R_{\mathrm{Cl}}$ when ClopHensorN is saturated with $\mathrm{Cl}^{-}$. As demonstrated in Figure 2F, $\alpha_{2} R_{\text {bound }}\left[\mathrm{pH}_{\mathrm{i}}\right]$ was also found to depend 
A

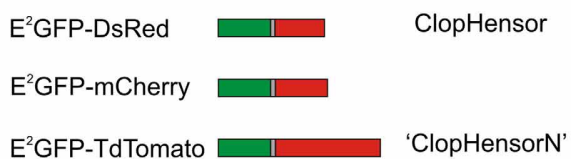

C

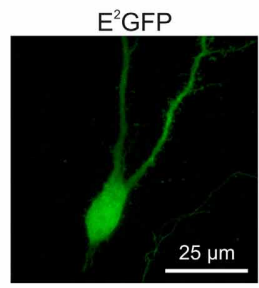

E

Day 2 post transfection
B

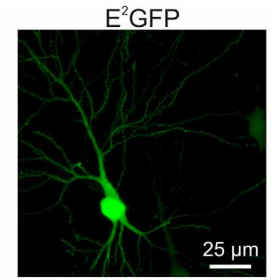

D

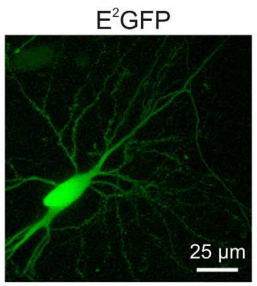

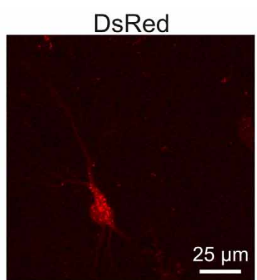

TdTomato

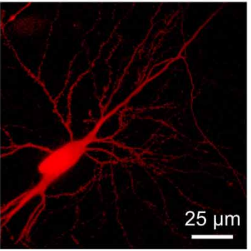

$\mathbf{F}$

Day 5 post transfection

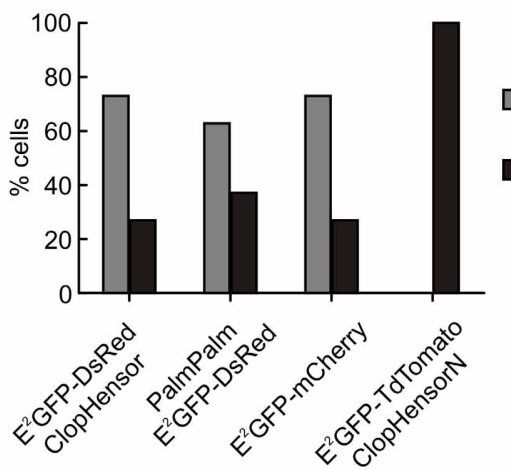

aggregates

no aggregates

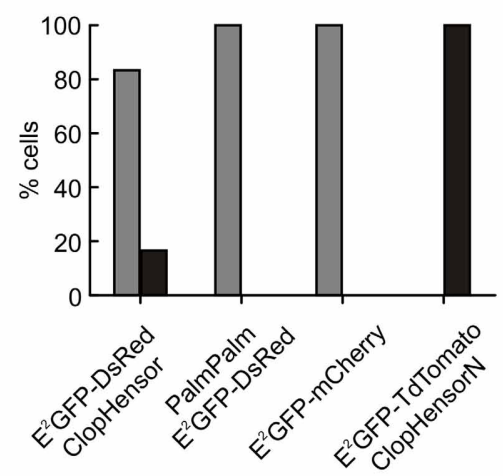

G

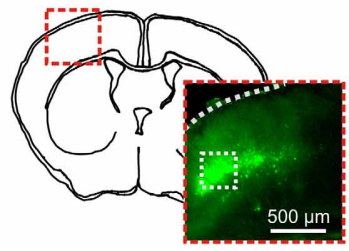

$458 \mathrm{~nm}$

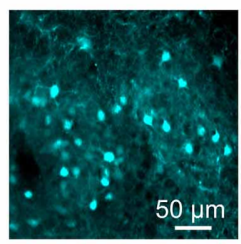

$488 \mathrm{~nm}$

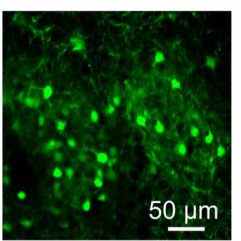

$594 \mathrm{~nm}$

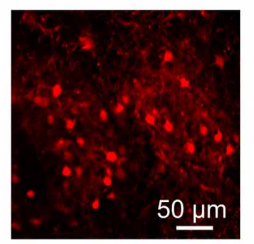

FIGURE 1 | ClopHensorN: a genetically-encoded $\mathrm{Cl}^{-}$and $\mathrm{pH}$ sensor optimized for use in the nervous system. (A) Biolistic transfection of hippocampal slices was used to test different fusion proteins for use as a simultaneous $\mathrm{Cl}^{-}$and $\mathrm{pH}$ sensor in the nervous system. These were composed of $E^{2}$ GFP (green) fused to one of three different red fluorescent proteins (RFPs; red) via a flexible linker (gray). The RFP was either DsRed ("ClopHensor"; top), mCherry (middle), or TdTomato ("ClopHensorN"; bottom). (B) A hippocampal CA3 pyramidal neuron expressing ClopHensor. The E ${ }^{2}$ GFP (left) shows uniform expression but the DsRed (right) revealed marked intracellular aggregation and poor co-localization with the $E^{2} G F P$. (C) A CA3 pyramidal neuron expressing the $E^{2}$ GFP-mCherry fusion protein. Pronounced aggregation issues also affect this construct. (D) A CA3 pyramidal neuron expressing the $E^{2}$ GFP-TdTomato fusion protein

"ClopHensorN." ClopHensorN displayed homogenous expression of both $E^{2} \mathrm{GFP}$ and TdTomato, and complete co-localization of the two fluorophores. (E) Population data from hippocampal slices 2 days after biolistic transfection with four different ClopHensor variants; E2 GFP-DsRed (original ClopHensor), PalmPalm-E²GFP-DsRed (ClopHensor with a membrane targeting sequence-PalmPalm-ClopHensor), E2 GFP-mCherry and E2GFP-TdTomato (ClopHensorN). The majority of cells expressing $E^{2}$ GFP-DsRed (19 of 26 cells imaged), PalmPalm E2 GFP-DsRed (39 of 62 cells), and $E^{2}$ GFP-mCherry (19 of 26 cells) demonstrated dense aggregation of the red fluorophore. In contrast, no aggregates were detected in any of the cells expressing ClopHensorN (0 of 58 cells) and the two fluorophores exhibited uniform and corresponding expression. (F) 5 days post transfection, almost all cells expressing E2 GFP-DsRed (20 of 24 cells), PalmPalm E2 GFP-DsRed ( 24 of 24 cells) and E2 GFP-mCherry ( 50 of 50 cells) contained dense aggregates. In contrast, all cells expressing ClopHensorN ( 0 of 36 cells with dense aggregates) continued to demonstrate uniform expression. (G) In utero electroporation of ClopHensorN in mouse embryos resulted in long-term and uniform expression in cortical neurons. After 4 weeks in vivo, expression was assessed using acute brain slices. A schematic of a coronal mouse brain slice at P21 and low magnification fluorescent image (left) indicate the position of the ClopHensorNexpressing cortical cells. High magnification confocal images collected following excitation at 458, 488, and $594 \mathrm{~nm}$, respectively (right), show that ClopHensorN displays homogenous expression and co-localization of the two fluorophores in mature cortical neurons. 


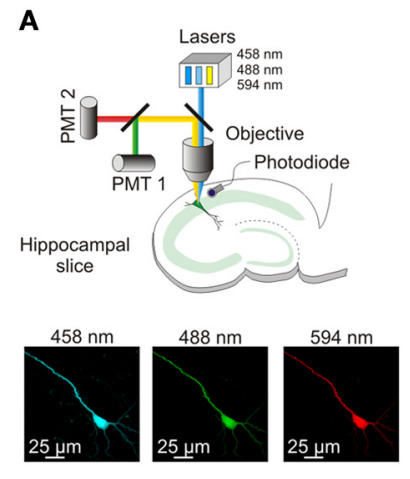

c

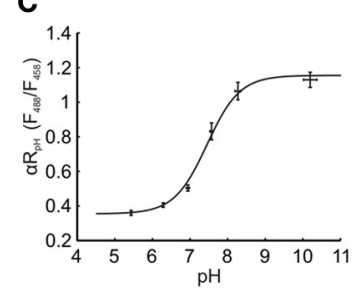

E

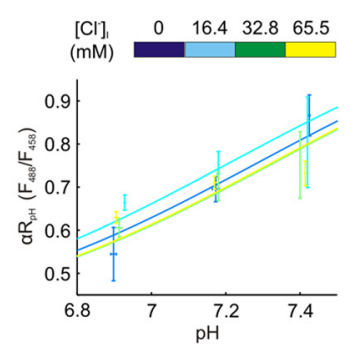

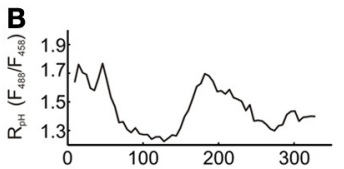
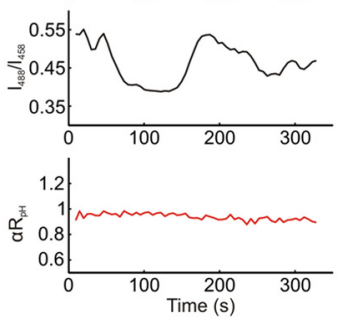

D

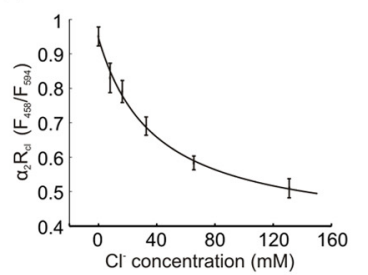

$\mathbf{F}$

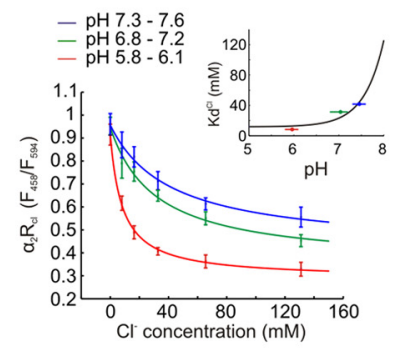

FIGURE 2 | Measuring intracellular $\mathrm{Cl}^{-}$and $\mathrm{pH}$ concentration using ClopHensorN. (A) Top, a schematic showing the experimental setup in which hippocampal pyramidal neurons expressing ClopHensorN were imaged. To determine $\left[\mathrm{Cl}^{-}\right]_{i}$ and $\mathrm{pH}_{i}$, confocal images were collected following excitation at 458, 488, and $594 \mathrm{~nm}$, respectively (bottom). (B) Lasers exhibit fluctuations over seconds and minutes, which affects real-time ratiometric imaging by excitation and requires offline correction, as described previously (Zucker and Price, 2001; Arosio et al., 2010). A hippocampal neuron expressing ClopHensorN was imaged in the presence of ionophores and an ACSF that "clamps" intracellular $\mathrm{pH}\left(\mathrm{pH}_{\mathrm{i}}\right)$ and intracellular $\mathrm{Cl}^{-}$concentration $\left(\left[\mathrm{Cl}^{-}\right]_{\mathrm{i}}\right)$ at $7.8 \mathrm{pH}$ units and $8 \mathrm{mM}$, respectively, (see Materials and Methods). Despite $\mathrm{pH}$ being held at this constant value, significant apparent changes in $\mathrm{R}_{\mathrm{pH}}\left(\mathrm{F}_{488} / \mathrm{F}_{458}\right)$ were recorded over a period of $330 \mathrm{~s}$ (top trace). A photodiode placed below the tissue was used to continuously record the emission power of the lasers, which were then used to calculate the intensity ratio for the 488 laser and the 458 laser $\left(I_{488} / I_{458}\right.$, middle trace). Note the strong correlation between the fluctuations in this ratio and $\mathrm{R}_{\mathrm{pH}}$. Bottom trace (red), $\mathrm{R}_{\mathrm{pH}}$ was corrected offline by a factor $\alpha$, where $\alpha=0.5 \div\left(\mathrm{I}_{488} / \mathrm{l}_{458}\right)$. This resulted in a stable estimate of $\mathrm{pH}$ under these "clamped" conditions and confirmed the efficacy of this correction process. In all experiments $\alpha \mathrm{R}_{\mathrm{pH}}$ was used to determine intracellular $\mathrm{pH}$, and in a similar manner, $\alpha_{2}$ was used to correct $\mathrm{R}_{\mathrm{Cl}}$ in order to determine $\left[\mathrm{Cl}^{-}\right]_{i}$ (see Materials and Methods). (C) ClopHensorN calibration curve relating $\mathrm{pH}_{\mathrm{i}}$ to the $\mathrm{pH}$ sensitive excitation fluorescence ratio $\left(\alpha R_{p H}\right)$, following correction for laser power fluctuations. $\mathrm{pH}_{\mathrm{i}}$ was manipulated by adjusting extracellular $\mathrm{pH}$ in the presence of a $\mathrm{H}^{+}$ permeable ionophore, data was fit using established equations (Grynkiewicz et al., 1985; Arosio et al., 2010) (see Equation 2, Materials and Methods) and $\mathrm{pK}_{\mathrm{a}}$ was found to be 7.45 with a fitted $95 \%$ confidence

(Continued)

\section{FIGURE 2 | Continued}

interval (Cl) between 7.29 and 7.62. (D) ClopHensorN calibration curve relating $\left[\mathrm{Cl}^{-}\right]_{i}$ to the $\mathrm{Cl}^{-}$sensitive excitation fluorescence ratio $\left(\alpha_{2} \mathrm{R}_{\mathrm{Cl}}\right)$, following correction for laser power fluctuations. $\left[\mathrm{Cl}^{-}\right]_{i}$ was systematically varied by controlling extracellular $\mathrm{Cl}^{-}$in the presence of a $\mathrm{Cl}^{-}$permeable ionophore, data was fit using established equations (see Equation 5, Materials and Methods) and $\mathrm{K}_{d}$ found to be $39.2 \mathrm{mM}$ with a fitted $95 \% \mathrm{Cl}$ between 11.7 and $66.7 \mathrm{mM}$. Error bars indicate SEM. (E) Varying $\left[\mathrm{Cl}^{-}\right]_{\mathrm{i}}$ within the physiological range had no effect on $\alpha \mathrm{R}_{\mathrm{pH}}$. (F) Consistent with previous studies using E2 GFP (Bizzarri et al., 2006; Arosio et al., 2010), pH changes influence the affinity of ClopHensorN for $\mathrm{Cl}^{-} . \mathrm{Kd}_{d}^{\mathrm{Cl}}$ shifted from 8.3 $\mathrm{mM}$ with a fitted $95 \% \mathrm{Cl}$ between 3.6 and $13.0 \mathrm{mM}$ (pH range 5.8-6.1) to $31.3 \mathrm{mM}$ and $41.7 \mathrm{mM}$ at pH ranges $6.8-7.2$ and $7.3-7.6$, respectively. The fitted $95 \% \mathrm{Cl}$ intervals for these $\mathrm{K}_{\mathrm{d}} \mathrm{S}$ were 4.9 to $57.8 \mathrm{mM}$ and -2.3 to $85.7 \mathrm{mM}$. The inset demonstrates the calculated dependence of $\mathrm{K}_{\mathrm{d}}^{\mathrm{Cl}}$ on $\mathrm{pH}$ (using Equation 6, See Materials and Methods). The $3 \mathrm{~K}_{d}^{\mathrm{Cl}}$ values for the 3 $\mathrm{pH}$ ranges (horizontal bars) are shown. Utilizing this calibration data, ClopHensorN could be used to accurately and simultaneously report $\left[\mathrm{Cl}^{-}\right]_{\mathrm{i}}$ and $\mathrm{pH}_{\mathrm{i}}$.

on $\mathrm{pH}$. Calibration data was then fitted using the following rearranged version of Equation 4:

$$
\alpha_{2} \mathrm{R}_{\mathrm{Cl}}=\left(\frac{\left[\mathrm{Cl}^{-}\right]_{\mathrm{i}} \alpha_{2} R_{\text {bound }}\left[\mathrm{pH}_{\mathrm{i}}\right]+K_{\mathrm{d}}^{\mathrm{Cl}}\left[\mathrm{pH}_{\mathrm{i}}\right] \alpha_{2} R_{\text {free }}}{K_{\mathrm{d}}^{\mathrm{Cl}}\left[\mathrm{pH}_{\mathrm{i}}\right]+\left[\mathrm{Cl}^{-}\right]_{\mathrm{i}}}\right)
$$

This allowed $K_{\mathrm{d}}^{\mathrm{Cl}}\left[\mathrm{pH}_{\mathrm{i}}\right], \alpha_{2} R_{\text {free }}$ and $\alpha_{2} R_{\text {bound }}\left[\mathrm{pH}_{\mathrm{i}}\right]$ to be determined by performing $\mathrm{Cl}^{-}$calibrations at different $\mathrm{pH}_{\mathrm{i}}$ values (see Figure $2 \mathrm{~F}) . K_{\mathrm{d}}^{\mathrm{Cl}}\left[\mathrm{pH}_{\mathrm{i}}\right]$ can be described according to the following equation (Arosio et al., 2007, 2010):

$$
\mathrm{K}_{\mathrm{d}}^{\mathrm{Cl}}\left[\mathrm{pH}_{\mathrm{i}}\right]={ }^{1} \mathrm{~K}_{\mathrm{d}}^{\mathrm{Cl}}\left(\frac{1+10^{\left(\mathrm{pK}_{\mathrm{A}}-\mathrm{pH}_{\mathrm{i}}\right)}}{10^{\left(\mathrm{pK}_{\mathrm{A}}-\mathrm{pH}_{\mathrm{i}}\right)}}\right)
$$

${ }^{1} \mathrm{~K}_{\mathrm{d}}^{\mathrm{Cl}}$ reflects the $\mathrm{Cl}^{-}$dissociation constant when ClopHensorN is in its most acidic form (fully protonated) and was determined by fitting Equation 5 with $\mathrm{K}_{\mathrm{d}}^{\mathrm{Cl}}\left[\mathrm{pH}_{\mathrm{i}}\right]$ data derived from Equation 4. This allowed $\mathrm{K}_{\mathrm{d}}^{\mathrm{Cl}}\left[\mathrm{pH}_{\mathrm{i}}\right]$ to be determined for any $\mathrm{pH}_{\mathrm{i}}$. $\alpha_{2} R_{\text {free }}$ was constant irrespective of $\mathrm{pH}_{\mathrm{i}}$. The relationship between $\alpha_{2} R_{\text {bound }}\left[\mathrm{pH}_{\mathrm{i}}\right]$ and $\mathrm{pH}_{\mathrm{i}}$ was assumed to be linear and also fit using data from Equation 4.

$$
\alpha_{2} R_{\text {bound }}\left[\mathrm{pH}_{\mathrm{i}}\right]=M\left(\mathrm{pH}_{\mathrm{i}}\right)+\alpha_{2} R_{\text {bound }}, \mathrm{pH}_{0}
$$

No weighting was used during the fitting procedures. Calibration data was acquired from ClopHensorN-expressing cells in hippocampal slices. Intracellular $\mathrm{pH}$ and $\mathrm{Cl}^{-}$were controlled by equilibrating extra- and intracellular ion concentrations using the $\mathrm{K}^{+} / \mathrm{H}^{+}$exchanger nigericin $(10 \mu \mathrm{M})$ and the $\mathrm{Cl}^{-} / \mathrm{OH}^{-}$ exchanger tributyltinchloride $(10 \mu \mathrm{M})$ in a high $\mathrm{K}^{+}$containing ACSF, according to the method described previously by Boyarsky et al. (1988). ACSF of different $\left[\mathrm{Cl}^{-}\right]$were made by mixing two HEPES buffered ACSF solutions containing $0 \mathrm{mM}$ or $131 \mathrm{mM} \mathrm{Cl}^{-}$, respectively. The $0 \mathrm{mM} \mathrm{Cl}^{-}$solution contained (in $\mathrm{mM}$ ): potassium D-gluconate (123), HEPES (23), D-glucose (11), $\mathrm{NaH}_{2} \mathrm{PO}_{4}$ (1.2), $\mathrm{MgSO}_{4}$ (2) and calcium D-gluconate (2). The $131 \mathrm{mM} \mathrm{Cl}^{-}$solution contained (in $\mathrm{mM}$ ): $\mathrm{KCl}$ (123), HEPES (23), D-glucose (11), $\mathrm{NaH}_{2} \mathrm{PO}_{4}$ (1.2), $\mathrm{MgCl}_{2}$ (2) and $\mathrm{CaCl}_{2}$ 
(2). Using these two solutions high $\mathrm{K}^{+}$containing ACSF solutions of the following $\mathrm{Cl}^{-}$concentrations were made: 131, 65.5, $32.75,16.375,8 \mathrm{mM}$, and $0 \mathrm{mM}$. $\mathrm{pH}$ was adjusted with small aliquots of $\mathrm{NaOH}$ and, to avoid $\mathrm{CO}_{2}$-dependent $\mathrm{pH}$ buffering, ACSF was bubbled with $100 \% \mathrm{O}_{2}$. After each adjustment of either $\mathrm{Cl}^{-}$or $\mathrm{pH}$, at least $15 \mathrm{~min}$ were allowed for intracellular and extracellular compartments to equilibrate. For calibration purposes, this allowed the measurement of $\alpha \mathrm{R}_{\mathrm{pH}}$ and $\alpha_{2} R_{\mathrm{Cl}}$ at different, known $\left[\mathrm{Cl}^{-}\right]_{\mathrm{i}}$ and $\mathrm{pH}_{\mathrm{i}}$. For all experimental data, (i.e., for each time point of a trace), $\mathrm{pH}_{\mathrm{i}}$ was first determined from $\alpha \mathrm{R}_{\mathrm{pH}}$ using Equation 1. Using $\mathrm{pH}_{\mathrm{i}}, \mathrm{K}_{\mathrm{d}}^{\mathrm{Cl}}\left[\mathrm{pH}_{\mathrm{i}}\right]$ and $R_{\text {bound }}\left[\mathrm{pH}_{\mathrm{i}}\right]$ were then calculated from Equations 6 and 7. Finally, this allowed $\left[\mathrm{Cl}^{-}\right]_{\mathrm{i}}$ to be determined using $\alpha_{2} R_{\mathrm{Cl}}$ and Equation 4 (see Results).

\section{RESULTS}

\section{ClopHensorN: A GENETICALLY-ENCODED Cl- AND pH SENSOR OPTIMIZED FOR USE WITHIN THE NERVOUS SYSTEM}

Recently Arosio et al. (2010) engineered a novel fusion protein capable of independently and simultaneously measuring $\mathrm{Cl}^{-}$and $\mathrm{pH}$. Named ClopHensor, this reporter is based on the fusion of a well-described $\mathrm{pH}$ and $\mathrm{Cl}^{-}$sensitive GFP mutant $\mathrm{E}^{2} \mathrm{GFP}$ (Bizzarri et al., 2006), with the $\mathrm{pH}$ and $\mathrm{Cl}^{-}$ insensitive monomer DsRed (Figure 1A). The corresponding intracellular expression of $\mathrm{E}^{2} \mathrm{GFP}$ and DsRed is critical to ClopHensor's function as a ratiometric reporter of intracellular ion concentration. To test whether ClopHensor could be used to measure $\mathrm{Cl}^{-}$and $\mathrm{H}^{+}$in neurons, rat hippocampal brain slices were biolistically transfected with ClopHensorexpressing plasmids (Figure 1). Expression of ClopHensor or PalmPalm-ClopHensor in hippocampal pyramidal neurons often resulted in uniform $\mathrm{E}^{2} \mathrm{GFP}$ expression, but highly heterogeneous DsRed expression that occurred as dense intracellular aggregations (Figures 1B,E,F). This was associated with compromised cellular morphology and is consistent with previous reports that DsRed is susceptible to aggregation, particularly within fusion proteins (Shaner et al., 2005). In an attempt to address this issue we designed new fusion proteins where the DsRed monomer in the original ClopHensor was replaced with either mCherry or tandem dimer tomato (TdTomato; Figures 1A,C,D). Interestingly, like the original ClopHensor, the $\mathrm{E}^{2} \mathrm{GFP}-\mathrm{mCherry}$ fusion exhibited intracellular aggregations and a lack of colocalization between the two fluorophores (Figures 1C,E,F). In contrast, the $\mathrm{E}^{2} \mathrm{GFP}$-tdTomato fusion protein exhibited uniform and corresponding expression between the two fluorophores (Figures 1D-F). Whilst the other fusion proteins showed aggregations in more than $60 \%$ of the cells examined, this was not the case in any of the $\mathrm{E}^{2} \mathrm{GFP}$-tdTomato-expressing cells (Figures 1E,F). To further confirm that $\mathrm{E}^{2} \mathrm{GFP}$-tdTomato is welltolerated, we delivered the construct in vivo by in utero electroporation and confirmed that this resulted in uniform and widespread expression in mature cortical neurons (Figure 1G). Together these data confirm that the $\mathrm{E}^{2} \mathrm{GFP}$-tdTomato construct is well-suited for studies in the nervous system and has the potential to afford ratiometric simultaneous reporting of neuronal $\mathrm{Cl}^{-}$and $\mathrm{H}^{+}$. We have named this new fusion protein "ClopHensorN."

\section{ClopHensorN ALLOWS INDEPENDENT MEASUREMENT OF INTRACELLULAR $\mathrm{CI}^{-}$AND pH}

We then assessed the ability of ClopHensorN to independently report steady-state $\mathrm{Cl}^{-}$and $\mathrm{pH}$ in hippocampal pyramidal neurons. ClopHensorN was used as a ratiometric indicator of $\mathrm{Cl}^{-}$ and $\mathrm{pH}$ by excitation (Arosio et al., 2010) and was excited sequentially via excitation at 458,488 and $594 \mathrm{~nm}$ using a confocal microscope (Figure 2A). To compensate for fluctuations in laser intensity, a photodiode was used to record laser power output during imaging (Zucker and Price, 2001; Arosio et al., 2010) and the resulting data was used to correct fluorescence ratios offline by a factor $\alpha$ (for $\mathrm{R}_{\mathrm{pH}}$ ) and $\alpha_{2}$ (for $\mathrm{R}_{\mathrm{Cl}}$ ) (see Figure 2B and Materials and Methods). Calibration of the reporter was performed by systematically varying extracellular $\mathrm{Cl}^{-}$and $\mathrm{pH}$ in the presence of $\mathrm{H}^{+}$and $\mathrm{Cl}^{-}$permeable ionophores, which are known to equilibrate intra- and extracellular concentrations of these two ions. $\alpha \mathrm{R}_{\mathrm{pH}}$ was shown to depend upon intracellular $\mathrm{pH}$ with a $\mathrm{pKa}$ of 7.45 (Figure 2C). Importantly, systematically varying the intracellular $\mathrm{Cl}^{-}$across the physiological range $(0-65.5 \mathrm{mM})$, did not affect the $\alpha \mathrm{R}_{\mathrm{pH}}$ measurements. There was no correlation between intracellular $\mathrm{Cl}^{-}$and $\alpha \mathrm{R}_{\mathrm{pH}}$ for the three $\mathrm{pH}$ values tested (for $\mathrm{pH}$ 6.85-6.94, $P=0.15$, for $\mathrm{pH} 7.14-7.22, P=0.73$ and for $\mathrm{pH} 7.14$ $7.22, P=0.11$, Pearson Correlation, Figure 2E). Thus, consistent with previous work, $\mathrm{E}^{2} \mathrm{GFP}$ and hence ClopHensorN provides a $\mathrm{Cl}^{-}$insensitive readout of $\mathrm{pH}$ (Bizzarri et al., 2006; Arosio et al., 2010; Raimondo et al., 2012b). In order to report $\mathrm{Cl}^{-}$, ClopHensor derived proteins make use of the fact that $\mathrm{E}^{2} \mathrm{GFP}$ possesses a $\mathrm{pH}$ isobestic point at $458 \mathrm{~nm}$ (Arosio et al., 2010). Fluorescence emission at this excitation wavelength is $\mathrm{Cl}^{-}$sensitive, but not $\mathrm{pH}$ sensitive. Like DsRed, TdTomato's insensitivity to both $\mathrm{Cl}^{-}$and $\mathrm{pH}$ (Shaner et al., 2004) make it a suitable partner for ratiometric imaging. ClopHensorN was therefore used to report $\mathrm{Cl}^{-}$by calculating the ratio of fluorescence emission when $\mathrm{E}^{2} \mathrm{GFP}$ was excited at $458 \mathrm{~nm}$, over the emission when TdTomato was excited at $594 \mathrm{~nm}\left(\mathrm{R}_{\mathrm{Cl}}=\mathrm{F}_{458} / \mathrm{F}_{594}\right)$ and corrected for laser power fluctuations to generate $\alpha_{2} \mathrm{R}_{\mathrm{Cl}}$. Consistent with our predictions, $\alpha_{2} \mathrm{R}_{\mathrm{Cl}}$ was strongly sensitive to $\left[\mathrm{Cl}^{-}\right]_{\mathrm{i}}$ (Figure 2D). In agreement with previous studies using $\mathrm{E}^{2} \mathrm{GFP}, \mathrm{pH}$ changes influenced the affinity of ClopHensorN for $\mathrm{Cl}^{-}$(Bizzarri et al., 2006; Arosio et al., 2010), which could be accounted for by using the family of calibration curves (Figure 2F; see Materials and Methods). At low $\mathrm{pH}$, (range 5.8-6.1), whereby the sensor approaches full protonation, the affinity for $\mathrm{Cl}^{-}$is high with a $\mathrm{K}_{\mathrm{d}}^{\mathrm{Cl}}$ of $8.3 \mathrm{mM}$. Due to the fact that $\mathrm{E}^{2} \mathrm{GFP}$ requires a proton to be bound in order to bind $\mathrm{Cl}^{-}$, at higher intracellular $\mathrm{pH}$ the affinity of $\mathrm{E}^{2} \mathrm{GFP}$ for $\mathrm{Cl}^{-}$drops (Arosio et al., 2010). Indeed, at more physiological $\mathrm{pH}$ levels $\mathrm{K}_{\mathrm{d}}^{\mathrm{Cl}}$ was $31.3 \mathrm{mM}(\mathrm{pH}$ range 6.8-7.2) and $41.7 \mathrm{mM}$ (pH range 7.3-7.6). In summary, ClopHensorN allowed absolute neuronal $\mathrm{Cl}^{-}$concentration and $\mathrm{pH}$ to be determined simultaneously from fluorescence ratios $\left(\alpha \mathrm{R}_{\mathrm{Cl}}\right.$ and $\left.\alpha_{2} \mathrm{R}_{\mathrm{pH}}\right)$, in a manner that is independent of protein expression levels. This was achieved by: (1) calculating $\mathrm{pH}$ in a region of interest from $\alpha \mathrm{R}_{\mathrm{pH}}$, (2) using this value to calculate the $\mathrm{pH}$-dependent $\mathrm{Cl}^{-}$ binding parameters of ClopHensorN, and (3) using these parameters to calculate $\left[\mathrm{Cl}^{-}\right]_{\mathrm{i}}$ from $\alpha_{2} \mathrm{R}_{\mathrm{Cl}}$. This method establishes ClopHensorN as an important new tool for quantifying $\mathrm{Cl}^{-}$and $\mathrm{H}^{+}$concentrations in neurons. 


\section{FUNCTIONAL DISSOCIATION OF INTRACELLULAR Cl- AND pH MEASUREMENTS WITH ClopHensorN}

Genetically-encoded reporters of $\mathrm{Cl}^{-}$, which are currently available for use within the nervous system, are unable to discriminate between changes in $\left[\mathrm{Cl}^{-}\right]_{\mathrm{i}}$ and $\mathrm{pH}_{\mathrm{i}}$ (Kuner and Augustine, 2000; Markova et al., 2008; Raimondo et al., 2012b). To verify that ClopHensorN is able to dissociate $\left[\mathrm{Cl}^{-}\right]_{\mathrm{i}}$ and $\mathrm{pH}_{\mathrm{i}}$ we performed a series of experiments in ClopHensorN-expressing CA1 and CA3 hippocampal pyramidal neurons, in which we induced different activity-dependent ion fluxes. First, as $\mathrm{GABA}_{\mathrm{A}}$ receptors are primarily permeable to $\mathrm{Cl}^{-}$and to a lesser extent $\mathrm{HCO}_{3}^{-}$, strong $\mathrm{GABA}_{\mathrm{A}}$ receptor activation is predicted to generate a transient increase in $\left[\mathrm{Cl}^{-}\right]_{\mathrm{i}}$ and an acidic $\mathrm{pH}$ transient due to $\mathrm{HCO}_{3}^{-}$efflux (Kaila et al., 1989). Consistent with this prediction, both agonist activation of $\mathrm{GABA}_{\mathrm{A}}$ receptors by application of GABA $(200 \mu \mathrm{M}$, $20 \mathrm{~ms}$ ) and synaptic activation of $\mathrm{GABA}_{\mathrm{A}}$ receptors via electrical stimulation of GABAergic afferents, resulted in a transient increase in $\left[\mathrm{Cl}^{-}\right]_{\mathrm{i}}$ and a modest acidification (Figures 3A,B). Second, we performed ion substitution experiments in which synchronous network activity was elicited by bathing the hippocampal slices in either a $\mathrm{Mg}^{2+}$-free $\mathrm{ACSF}$ or a $\mathrm{Cl}^{-}$-free ACSF; (see Materials and Methods). As the substitution of extracellular $\mathrm{Cl}^{-}$would remove the driving force for this ion to enter cells, we predicted that the two ACSF solutions would significantly alter the ion dynamics measured via ClopHensorN. Whilst imaging the ClopHensorN-expressing pyramidal neurons, synchronous network activity was monitored via a whole cell patch recording from a nearby pyramidal neuron $(<200 \mu \mathrm{m}$ between somata). Consistent with previous reports, network activity in the $\mathrm{Mg}^{2+}$ free ACSF generated intracellular acidic transients in the imaged neuron (Raimondo et al., 2012b) and robust accumulation of intracellular $\mathrm{Cl}^{-}$(Figure 3C), presumably due to $\mathrm{Cl}^{-}$infux via activated $\mathrm{GABA}_{\mathrm{A}}$ receptors (Ilie et al., 2012). In contrast, when the same neuron was imaged in the $\mathrm{Cl}^{-}$-free ACSF, synchronous network activity continued to generate acidic transients but the activity-dependent $\mathrm{Cl}^{-}$influxes were now replaced by smaller $\mathrm{Cl}^{-}$effluxes (Figure 3D). This is consistent with the predicted change in transmembrane driving force for $\mathrm{Cl}^{-}$. Taken together, these sets of experiments confirmed the ability of ClopHensorN to dissociate changes in $\mathrm{Cl}^{-}$and $\mathrm{H}^{+}$in the nervous system.

\section{ClopHensorN DISSOCIATES ACTIVITY-DEPENDENT Cl- AND pH DYNAMICS IN HIPPOCAMPAL NEURONS}

Having established the potential of ClopHensorN to dissociate simultaneous ion dynamics in the nervous system, we conducted a quantitative study of the magnitude and kinetics of activity-dependent changes in $\left[\mathrm{Cl}^{-}\right]_{\mathrm{i}}$ and $\mathrm{pH}_{\mathrm{i}}$. Synchronous network activity was induced in hippocampal slices by removing $\mathrm{Mg}^{2+}$ from the slice perfusate. ClopHensorN-expressing CA1 and CA3 pyramidal neurons were imaged concurrently with whole cell patch-clamp recordings from neighboring cells to provide a simultaneous readout of network activity. Network events resulted in a highly significant positive shift in $\left[\mathrm{Cl}^{-}\right]_{\mathrm{i}}$ $(P<0.0001, t$-test, $n=75$ network events from 16 neurons $)$ and an acidic shift in $\mathrm{pH}_{\mathrm{i}}(P<0.0001, t$-test, Figures $4 \mathrm{~A}, \mathbf{B})$. Even short periods of network activity caused detectable shifts in intracellular $\mathrm{Cl}^{-}$and $\mathrm{pH}$ (Figure 4A). For instance, network events lasting $1-3 \mathrm{~s}$ caused a peak increase in $\left[\mathrm{Cl}^{-}\right]_{\mathrm{i}}$ of $2.2 \pm$
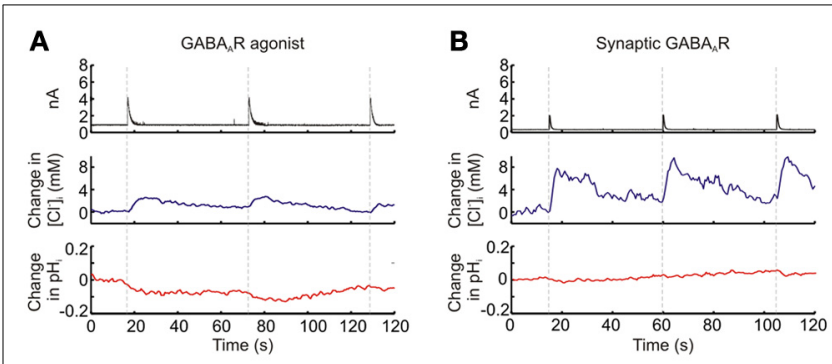

C

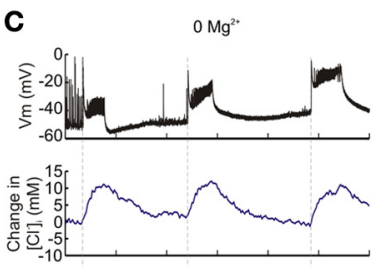

D
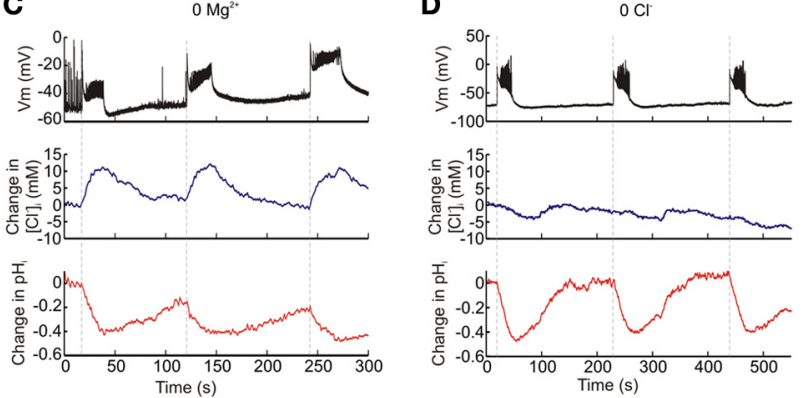

FIGURE 3 | Functional dissociation of intracellular $\mathrm{Cl}^{-}$and $\mathrm{pH}$ with ClopHensorN. Hippocampal pyramidal neurons expressing ClopHensorN were imaged whilst simultaneous patch clamp recordings were performed either from the ClopHensorN-expressing cell (" $a$ " and " $b$ ") or a neighboring

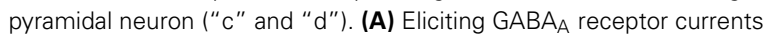
(black trace, top) via focal delivery of GABA (200 $\mu \mathrm{M}, 20 \mathrm{~ms})$ resulted in both transient increases in $\left[\mathrm{Cl}^{-}\right]_{i}$ (blue trace, middle) and intracellular acidic transients (red trace, bottom). (B) Similar $\mathrm{Cl}^{-}$and $\mathrm{H}^{+}$fluxes were observed when $\mathrm{GABA}_{A}$ receptors were activated via stimulation of monosynaptic GABAergic inputs to the ClopHensorN-expressing neuron. (C) An ion substitution experiment was performed to confirm independent $\left[\mathrm{Cl}^{-}\right]_{i}$ and $\mathrm{pH}_{\mathrm{i}}$ measurements using ClopHensorN. Synchronous network events were induced in hippocampal brain slices via bath application of a $\mathrm{Mg}^{2+}$-free ACSF. A ClopHensorN-expressing hippocampal neuron was imaged whilst network events were monitored via a whole-cell patch recording from a nearby neuron ( $<200 \mu \mathrm{m}$ between somata; black trace, top). The onset of network events (vertical dashed lines) correlated with the onset of intracellular $\mathrm{Cl}^{-}$accumulation (blue trace, middle) and intracellular acidification (red trace, bottom). (D) $\left[\mathrm{Cl}^{-}\right]_{i}$ and $\mathrm{pH}_{\mathrm{i}}$ measurements from the same neuron in "C," following the replacement of the $\mathrm{Mg}^{2+}$-free ACSF with a $\mathrm{Cl}^{-}$-free ACSF. Network events (black trace, top) were again correlated with intracellular acidification. However, rather than $\mathrm{Cl}^{-}$influxes, smaller $\mathrm{Cl}^{-}$effluxes were now associated with the network events.

$0.7 \mathrm{mM}$ and a $0.017 \pm 0.003 \mathrm{pH}$ unit decrease in $\mathrm{pH}_{\mathrm{i}}(P=0.008$ and $P<0.0001, t$-test). Furthermore, the magnitude of the peak increase in $\left[\mathrm{Cl}^{-}\right]_{\mathrm{i}}$ and decrease in $\mathrm{pH}_{\mathrm{i}}$ was tightly correlated with the length of the recorded network event $\left(\left[\mathrm{Cl}^{-}\right]_{\mathrm{i}}: r=0.5792\right.$, $P<0.0001, \mathrm{pH}_{\mathrm{i}}: r=-0.7487, P<0.0001$, Pearson Correlation, Figure 4B). The slope of the linear fit revealed a $0.43 \mathrm{mM}$ increase in peak $\left[\mathrm{Cl}^{-}\right]_{\mathrm{i}}$ per second of network activity. Conversely, the slope of the linear fit for peak change in $\mathrm{pH}_{\mathrm{i}}$ revealed a decrease of $0.008 \mathrm{pH}$ units per second of network activity (Figure 4B).

Utilizing ClopHensorN we were able to detect statistically significant increases in neuronal $\left[\mathrm{Cl}^{-}\right]_{i}$ within $1.5 \mathrm{~s}$ of the onset of network activity (the maximum sample rate; see Materials and Methods; $P=0.0007, n=37$ events, $t$-test, Figure 5A). Likewise intracellular acidification could also be detected within $1.5 \mathrm{~s}$ of the onset of elevated network activity $(P=0.0007$ for neurons, $t$-test, Figure 5A). This demonstrates the rapidity with which 


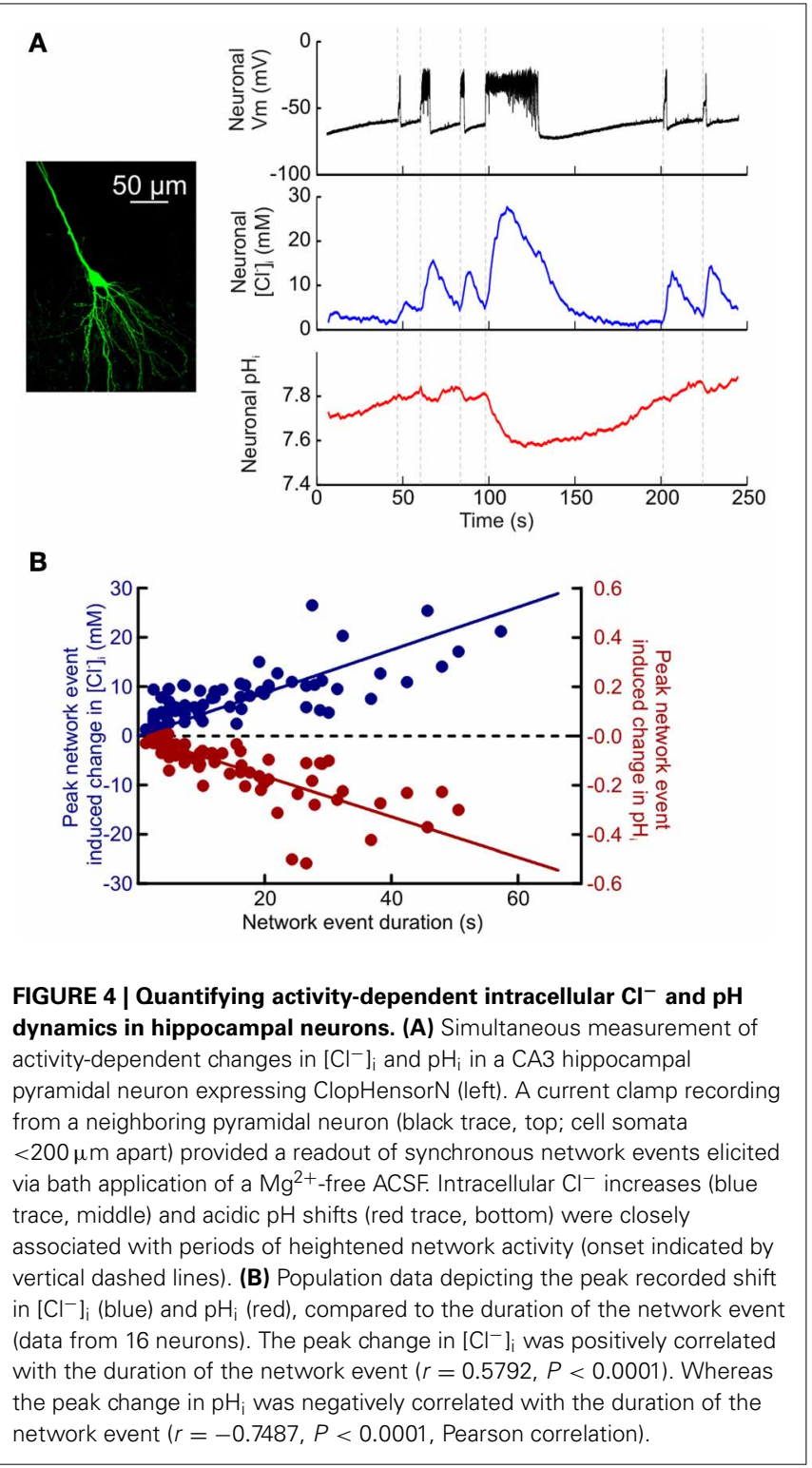

intracellular $\mathrm{Cl}^{-}$and $\mathrm{pH}$ changes could be monitored using ClopHensorN under our experimental conditions. Lastly, simultaneous, dynamic readout of $\left[\mathrm{Cl}^{-}\right]_{\mathrm{i}}$ and $\mathrm{pH}_{\mathrm{i}}$ allowed us to independently compare the kinetics of activity-dependent changes to neuronal $\mathrm{Cl}^{-}$and $\mathrm{pH}$ levels. Whilst the time to peak shift of intracellular ion concentration was not different between the two ions $(96.5 \pm 4.7$ and $104.6 \pm 4.7 \%$ of network event duration, $P=0.089, t$-test, Figure 5B), $\left[\mathrm{Cl}^{-}\right]_{\mathrm{i}}$ recovered to baseline levels significantly faster than $\mathrm{pH}_{\mathrm{i}}(219.6 \pm 15.4$ vs. $319.8 \pm 14.7 \%$ of network event duration, $P<0.0001, t$-test, Figure 5B). These experiments demonstrate the utility of using ClopHensorN for quantifying the size and temporal properties of $\mathrm{Cl}^{-}$and $\mathrm{H}^{+}$ion dynamics in neurons.

\section{DISCUSSION}

Here we present ClopHensorN-a genetically-encoded ratiometric $\mathrm{Cl}^{-}$and $\mathrm{pH}$ sensor that is optimized for use in the nervous
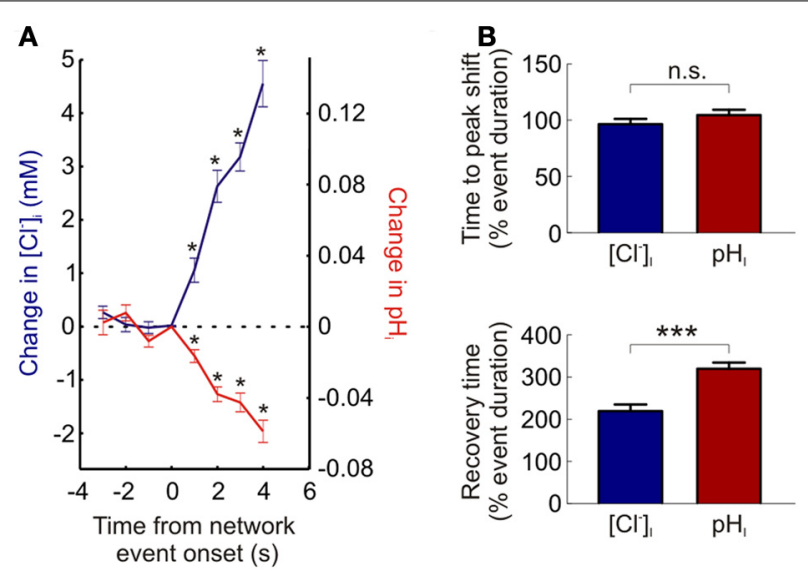

FIGURE 5 | The kinetics of activity-dependent changes in intracellular $\mathrm{Cl}^{-}$and $\mathrm{H}^{+}$. (A) ClopHensorN allows rapid detection of $\mathrm{Cl}^{-}$and $\mathrm{H}^{+}$ changes. The change in $\left[\mathrm{Cl}^{-}\right]_{i}$ (blue, left axis) and $\mathrm{pH}_{\mathrm{i}}$ (red, right axis) are plotted as a function of the onset of network events (duration $>4 \mathrm{~s}$ ). Significant changes in $\left[\mathrm{Cl}^{-}\right]_{\mathrm{i}}$ and $\mathrm{pH}_{\mathrm{i}}$ (asterisks) were detected within $1.5 \mathrm{~s}$ of the onset of elevated network activity (the maximum sample rate; see Materials and Methods). (B) Comparing the kinetics of activity-dependent $\left[\mathrm{Cl}^{-}\right]_{\mathrm{i}}$ (blue) and $\mathrm{pH}_{\mathrm{i}}$ (red) shifts in neurons. Whilst there was no significant difference between the time to peak shift in $\left[\mathrm{Cl}^{-}\right]_{\mathrm{i}}$ and $\mathrm{pH}_{\mathrm{i}}$ (top, n.s.

$P=0.089$, $t$-test), activity-dependent $\left[\mathrm{Cl}^{-}\right]_{\mathrm{i}}$ changes returned to baseline significantly faster than corresponding $\mathrm{pH}_{\mathrm{i}}$ transients (bottom,

${ }^{* * *} P<0.0001, t$-test). This indicates that separate mechanisms are likely to contribute to the regulation of these two ion species. Error bars indicate SEM.

system. ClopHensorN is shown to provide dynamic, simultaneous quantification of intracellular $\mathrm{Cl}^{-}$and $\mathrm{H}^{+}$concentrations under a variety of conditions. Furthermore, our measurements with ClopHensorN have identified previously unrecognized differences in the temporal dynamics of $\mathrm{Cl}^{-}$and $\mathrm{pH}$ concentrations, which become evident during periods of network activity. These features distinguish ClopHensorN from currently available reporters and highlight that ClopHensorN represents an important resource for monitoring ion dynamics in the nervous system. This reporter offers new opportunities to understand the regulation and roles played by $\mathrm{Cl}^{-}$and $\mathrm{H}^{+}$in processes such as synaptic transmission, cell morphology changes and metabolism.

ClopHensorN displays the cellular expression profile desired for a ratiometric reporter of intracellular ion concentration and exhibits signal to noise characteristics that are comparable to the best currently available reporters of either $\mathrm{Cl}^{-}$or $\mathrm{pH}$ (Raimondo et al., 2012b). ClopHensorN allowed us to detect significant intracellular $\mathrm{Cl}^{-}$and $\mathrm{pH}$ changes within our minimum sampling interval $(1.5 \mathrm{~s})$. In addition, the reporter displays good photostability with measurements exhibiting negligible drift due to photobleaching, which has been a limitation for other reporters (Bregestovski et al., 2009). These advantageous properties make ClopHensorN suitable for the measurement of both baseline and dynamic changes in $\mathrm{Cl}^{-}$and $\mathrm{pH}$. As with other fluorescent proteins, there is the opportunity to use genetic techniques to target ClopHensorN to specific cell types or subcellular compartments, and to combine the reporter with other molecular tools. 
$\mathrm{Cl}^{-}$and $\mathrm{H}^{+}$ions are often co-regulated (Russell and Boron, 1976; Kaila et al., 1989) and neuronal processes can generate fluxes of both ions (Chesler, 2003; Farrant and Kaila, 2007). Therefore, a fundamental advantage of ClopHensorN is that it generates measurements of both ion species and makes it possible to dissociate concentration changes that are occurring simultaneously. This feature of ClopHensorN was confirmed through ion substitution experiments and by detecting the intracellular $\mathrm{Cl}^{-}$and $\mathrm{H}^{+}$accumulation that accompanies intense $\mathrm{GABA}_{\mathrm{A}}$ receptor activation (Kaila et al., 1989). We then leveraged this capability to make the first simultaneous recordings of activitydependent intracellular $\mathrm{Cl}^{-}$and $\mathrm{pH}$ changes in the hippocampus. ClopHensorN revealed that network activity results in both intracellular $\mathrm{Cl}^{-}$and $\mathrm{H}^{+}$accumulation in neurons, but also revealed differences in the kinetics of these ionic shifts, with $\mathrm{pH}$ requiring longer to recover than $\mathrm{Cl}^{-}$changes. This is consistent with the idea that distinct cellular mechanisms contribute to the ongoing regulation of these ions and further illustrates the potential for the reporter to dissociate ion concentrations.

A further advantage of ClopHensorN over other genetic reporters is that it affords measurements of $\mathrm{Cl}^{-}$that are not confounded by $\mathrm{pH}$. Currently, the two most popular geneticallyencoded $\mathrm{Cl}^{-}$sensors are Clomeleon and the Clomeleon variant Cl-sensor (Kuner and Augustine, 2000; Markova et al., 2008). $\mathrm{Cl}^{-}$estimates using both of these sensors are affected by $\mathrm{pH}$, which means that concomitant $\mathrm{H}^{+}$fluxes will affect measurements. Using ClopHensorN we provide the first corrected measurements of $\left[\mathrm{Cl}^{-}\right]_{\mathrm{i}}$ within hippocampal neurons. Synchronous network activity was observed to cause rapid intracellular $\mathrm{Cl}^{-}$ accumulation in neurons. The intraneuronal $\mathrm{Cl}^{-}$accumulation that accompanies synchronous network activity will depolarize the reversal potential for $\mathrm{GABA}_{\mathrm{A}}$ receptors (Raimondo et al., 2012a). And it has been suggested that this activitydependent shift in inhibition ("ionic plasticity") (Rivera et al., 2005; Raimondo et al., 2012c) may regulate NMDA-dependent mechanisms of synaptic plasticity (Staley et al., 1995), improve the coherence of gamma oscillations (Vida et al., 2006) or result in the conversion of physiological activity into pathological epileptiform states (Wright et al., 2011; Lillis et al., 2012).

A disadvantage of ClopHensorN is that it is a reporter by excitation, which means that laser excitation intensity should be measured and correction algorithms used to account for independent fluctuations in the power of confocal laser lines. Lastly, the fact that $\mathrm{pH}$ affects the affinity of ClopHensorN for $\mathrm{Cl}^{-}$means that relatively complex procedures (see Materials and Methods) are required to correct $\mathrm{Cl}^{-}$ratios for concurrent $\mathrm{pH}$ fluctuations, with the potential for measurement artifacts to occur if performed incorrectly.

Nonetheless, ClopHensorN is the only available geneticallyencoded sensor that is able to measure both $\mathrm{Cl}^{-}$and $\mathrm{pH}$ within the nervous system-the location for some of the most dynamic changes in intracellular ion concentrations. We foresee future work in which ClopHensorN is used to dissect $\mathrm{Cl}^{-}$ and $\mathrm{H}^{+}$fluxes in specific cellular and subcellular compartments, and in the context of different processes in the nervous system.

\section{ACKNOWLEDGMENTS}

This manuscript is dedicated to the memory of the late Theresa Schlagheck, a special colleague and friend. We thank Daniele Arosio (University of Trento) for providing DNA constructs. We also thank the members of the Akerman lab for providing insightful comments and critically reading the manuscript. This work was supported by a grant from the Medical Research Council (G0601503), the Oxford Stem Cell Institute and the research leading to these results has received funding from the European Research Council under the European Community's Seventh Framework Programme (FP7/2007-2013), ERC grant agreement number 243273. Joseph V. Raimondo was supported by a Rhodes Scholarship, a NRF Innovation Postdoctoral Fellowship and a UCT URC Postdoctoral Fellowship. Bradley Joyce was supported by the Anatomical Society of Great Britain and Sarah E. Newey was supported by a Royal Society Dorothy Hodgkin Fellowship.

\section{REFERENCES}

Anderson, W. W., Lewis, D. V., Swartzwelder, H. S., and Wilson, W. A. (1986). Magnesium-free medium activates seizure-like events in the rat hippocampal slice. Brain Res. 398, 215-219. doi: 10.1016/0006-8993(86) 91274-6

Arosio, D., Garau, G., Ricci, F., Marchetti, L., Bizzarri, R., Nifosì, R., et al. (2007). Spectroscopic and structural study of proton and halide ion cooperative binding to GFP. Biophys. J. 93, 232-244. doi: 10.1529/biophysj.106.102319

Arosio, D., Ricci, F., Marchetti, L., Gualdani, R., Albertazzi, L., and Beltram, F. (2010). Simultaneous intracellular chloride and $\mathrm{pH}$ measurements using a GFP-based sensor. Nat. Methods 7, 516-518. doi: 10.1038/nmeth.1471

Awaji, T., and Hirasawa, A. (2001). Novel green fluorescent protein-based ratiometric indicators for monitoring $\mathrm{pH}$ in defined intracellular microdomains. Biochem. Biophys. Res. Commun. 289, 457-462. doi: 10.1006/bbrc.2001.6004

Bizzarri, R., Arcangeli, C., Arosio, D., Ricci, F., Faraci, P., Cardarelli, F., et al. (2006). Development of a novel GFP-based ratiometric excitation and emission $\mathrm{pH}$ indicator for intracellular studies. Biophys. J. 90, 3300-3314. doi: 10.1529/biophysj.105.074708

Boyarsky, G., Ganz, M. B., Sterzel, R. B., and Boron, W. F. (1988). pH regulation in single glomerular mesangial cells. I. Acid extrusion in absence and presence of HCO3-. Am. J. Physiol. 255, 844-856.

Bregestovski, P., Waseem, T., and Mukhtarov, M. (2009). Genetically encoded optical sensors for monitoring of intracellular chloride and chloride-selective channel activity. Front. Mol. Neurosci. 2:15. doi: 10.3389/neuro.02.015.2009

Chesler, M. (2003). Regulation and modulation of pH in the brain. Physiol. Rev. 83, 1183-1221. doi: 10.1152/physrev.00010.2003

Denker, S. P., and Barber, D. L. (2002). Cell migration requires both ion translocation and cytoskeletal anchoring by the Na-H exchanger NHE1. J. Cell. Biol. 159, 1087-1096. doi: 10.1083/jcb.200208050

Esposito, A., Gralle, M., Dani, M. A. C., Lange, D., and Wouters, F. S. (2008). pHlameleons: a family of FRET-based protein sensors for quantitative $\mathrm{pH}$ imaging. Biochemistry 47, 13115-13126. doi: 10.1021/bi8009482

Farrant, M., and Kaila, K. (2007). The cellular, molecular and ionic basis of GABAA receptor signalling. Prog. Brain Res. 160, 59-87. doi: 10.1016/S00796123(06)60005-8

Gatto, C., and Milanick, M. A. (1993). Inhibition of the red blood cell calcium pump by eosin and other fluorescein analogues. Am. J. Physiol. 264, C1577-C1586.

Grynkiewicz, G., Poenie, M., and Tsien, R. Y. (1985). A new generation of Ca2+ indicators with greatly improved fluorescence properties. J. Biol. Chem. 260, 3440-3450.

Hanson, G. T., McAnaney, T. B., Park, E. S., Rendell, M. E. P., Yarbrough, D. K., Chu, S., et al. (2002). Green fluorescent protein variants as ratiometric dual emission $\mathrm{pH}$ sensors. 1. Structural characterization and preliminary application. Biochemistry 41, 15477-15488. doi: 10.1021/bi026609p

Ilie, A., Raimondo, J. V., and Akerman, C. J. (2012). Adenosine release during seizures attenuates GABAA receptor-mediated depolarization. J. Neurosci. 32, 5321-5332. doi: 10.1523/JNEUROSCI.5412-11.2012 
Isomura, Y., Sugimoto, M., Fujiwara-Tsukamoto, Y., Yamamoto-Muraki, S., Yamada, J., and Fukuda, A. (2003). Synaptically activated Cl-accumulation responsible for depolarizing GABAergic responses in mature hippocampal neurons. J. Neurophysiol. 90, 2752. doi: 10.1152/jn.00142.2003

Jayaraman, S., Haggie, P., Wachter, R. M., Remington, S. J., and Verkman, A. S. (2000). Mechanism and cellular applications of a green fluorescent proteinbased halide sensor. J. Biol. Chem. 275, 6047-6050. doi: 10.1074/jbc.275.9.6047

Kaila, K., Pasternack, M., Saarikoski, J., Voipio, J., and Britain, G. (1989). Influence of GABA-gated bicarbonate conductance on potential, current and intracellular chloride in crayfish muscle fibres. J. Physiol. 416, 161-181.

Kuner, T., and Augustine, G. J. (2000). A genetically encoded ratiometric indicator for chloride: capturing chloride transients in cultured hippocampal neurons. Neuron 27, 447-459. doi: 10.1016/S0896-6273(00)00056-8

Lillis, K. P., Kramer, M. A., Mertz, J., Staley, K. J., and White, J. A. (2012). Pyramidal cells accumulate chloride at seizure onset. Neurobiol. Dis. 47, 358-366. doi: 10.1016/j.nbd.2012.05.016

Markova, O., Mukhtarov, M., Real, E., Jacob, Y., and Bregestovski, P. (2008). Genetically encoded chloride indicator with improved sensitivity. J. Neurosci. Methods 170, 67-76. doi: 10.1016/j.jneumeth.2007.12.016

Miesenböck, G., De Angelis, D. A., and Rothman, J. E. (1998). Visualizing secretion and synaptic transmission with $\mathrm{pH}$-sensitive green fluorescent proteins. Nature 394, 192-195. doi: 10.1038/28190

Mukhtarov, M., Liguori, L., Waseem, T., Rocca, F., Buldakova, S., Arosio, D., et al. (2013). Calibration and functional analysis of three genetically encoded Cl-/pH sensors. Front. Mol. Neurosci. 6:9. doi: 10.3389/fnmol.2013. 00009

Pouille, F., and Scanziani, M. (2001). Enforcement of temporal fidelity in pyramidal cells by somatic feed-forward inhibition. Science 293, 1159-1163. doi: 10.1126/science. 1060342

Putney, L. K., and Barber, D. L. (2003). Na-H exchange-dependent increase in intracellular pH times G2/M entry and transition. J. Biol. Chem. 278, 44645-44649. doi: 10.1074/jbc.M308099200

Raimondo, J. V., Kay, L., Ellender, T. J., and Akerman, C. J. (2012a). Optogenetic silencing strategies differ in their effects on inhibitory synaptic transmission. Nat. Neurosci. 15, 1102-1104. doi: 10.1038/nn.3143

Raimondo, J. V., Irkle, A., Wefelmeyer, W., Newey, S. E., and Akerman, C. J. (2012b). Genetically encoded proton sensors reveal activity-dependent $\mathrm{pH}$ changes in neurons. Front. Mol. Neurosci. 5:68. doi: 10.3389/fnmol.2012.00068

Raimondo, J. V., Markram, H., and Akerman, C. J. (2012c). Short-term ionic plasticity at GABAergic synapses. Front. Synaptic Neurosci. 4:5. doi 10.3389/fnsyn.2012.00005

Rivera, C., Voipio, J., and Kaila, K. (2005). Two developmental switches in GABAergic signalling: the $\mathrm{K}+-\mathrm{Cl}-$ cotransporter KCC2 and carbonic anhydrase CAVII. J. Physiol. 562, 27-36. doi: 10.1113/jphysiol.2004.077495

Russell, J., and Boron, W. (1976). Role of chloride transport in regulation of intracellular pH. Nature 264, 73-75. doi: 10.1038/264073a0
Shaner, N. C., Campbell, R. E., Steinbach, P. A., Giepmans, B. N. G., Palmer, A. E., and Tsien, R. Y. (2004). Improved monomeric red, orange and yellow fluorescent proteins derived from Discosoma sp. red fluorescent protein. Nat. Biotechnol. 22, 1567-1572. doi: 10.1038/nbt1037

Shaner, N. C., Steinbach, P. A., and Tsien, R. Y. (2005). A guide to choosing fluorescent proteins. Nat. Methods 2, 905-909. doi: 10.1038/nmeth819

Staley, K. J., Soldo, B. L., and Proctor, W. R. (1995). Ionic mechanisms of neuronal excitation by inhibitory GABAA receptors. Science 269, 977-981. doi: 10.1126/science.7638623

Stoppini, L., Buchs, P.-A., and Muller, D. (1991). A simple method for organotypic cultures of nervous tissue. J. Neurosci. Methods 37, 173-182. doi: 10.1016/01650270(91)90128-M

Tabb, J., Kish, P., Van Dyke, R., and Ueda, T. (1992). Glutamate transport into synaptic vesicles. Roles of membrane potential, $\mathrm{pH}$ gradient, and intravesicular pH. J. Biol. Chem. 267, 15412-15418.

Vida, I., Bartos, M., and Jonas, P. (2006). Shunting inhibition improves robustness of gamma oscillations in hippocampal interneuron networks by homogenizing firing rates. Neuron 49, 107-117. doi: 10.1016/j.neuron.2005.11.036

Wright, R., Raimondo, J. V., and Akerman, C. J. (2011). Spatial and temporal dynamics in the ionic driving force for GABA(A) receptors. Neural Plast. 2011, 728395. doi: 10.1155/2011/728395

Yamamoto, C., and Kawai, N. (1967). Seizure discharges evoked in vitro in thin section from guinea pig hippocampus. Science 155, 341-342. doi: 10.1126/science.155.3760.341

Zucker, R. M., and Price, O. (2001). Evaluation of confocal microscopy system performance. Cytometry 44, 273-294. doi: 10.1002/1097-0320(20010801)44: $4<273:$ :AID-CYTO1120>3.0.CO;2-N

Conflict of Interest Statement: The authors declare that the research was conducted in the absence of any commercial or financial relationships that could be construed as a potential conflict of interest.

Received: 02 October 2013; accepted: 17 October 2013; published online: 13 November 2013.

Citation: Raimondo JV, Joyce B, Kay L, Schlagheck T, Newey SE, Srinivas S and Akerman CJ (2013) A genetically-encoded chloride and $p H$ sensor for dissociating ion dynamics in the nervous system. Front. Cell. Neurosci. 7:202. doi: 10.3389/fncel. 2013.00202

This article was submitted to the journal Frontiers in Cellular Neuroscience. Copyright (c) 2013 Raimondo, Joyce, Kay, Schlagheck, Newey, Srinivas and Akerman. This is an open-access article distributed under the terms of the Creative Commons Attribution License (CC BY). The use, distribution or reproduction in other forums is permitted, provided the original author(s) or licensor are credited and that the original publication in this journal is cited, in accordance with accepted academic practice. No use, distribution or reproduction is permitted which does not comply with these terms. 